\title{
Incidence, characteristics and clinical relevance of acute stroke in old patients hospitalized with COVID-19
}

\author{
Aline Mendes ${ }^{1 *}$, François R. Herrmann¹, Laurence Genton², Christine Serratrice ${ }^{3}$, Emmanuel Carrera4
} Maria Isabel Vargas ${ }^{5}$, Gabriel Gold ${ }^{1}$, Christophe E. Graf ${ }^{6}$, Dina Zekry ${ }^{3}$ and Max Scheffler ${ }^{7}$

\begin{abstract}
Background: Stroke in the course of coronavirus disease (COVID-19) has been shown to be associated with more severe respiratory symptoms and higher mortality, but little knowledge in this regard exists on older populations. We aimed to investigate the incidence, characteristics, and prognosis of acute stroke in geriatric patients hospitalized with COVID-19.

Methods: A monocentric cross-sectional retrospective study of 265 older patients hospitalized with COVID-19 on acute geriatric wards. 11/265 presented a stroke episode during hospitalization. Mortality rates and two-group comparisons (stroke vs non-stroke patients) were calculated and significant variables added in logistic regression models to investigate stroke risk factors.

Results: Combined ischemic and hemorrhagic stroke incidence was $4.15 \% .72 .7 \%$ of events occurred during acute care. Strokes presented with altered state of consciousness and/or delirium in $81.8 \%$, followed by a focal neurological deficit in $45.5 \%$. Ischemic stroke was more frequently unilateral (88.8\%) and localized in the middle cerebral artery territory (55.5\%). Smoking and a history of previous stroke increased by more than seven (OR 7.44; $95 \% \mathrm{Cl} 1.75-31.64 ; p=0.007$ ) and five times (OR 5.19; $95 \% \mathrm{Cl} 1.50-17.92 ; p=0.009$ ), respectively, the risk of stroke. Each additional point in body mass index (BMI) reduced the risk of stroke by $14 \%$ (OR 0.86; $95 \% \mathrm{Cl} 0.74-0.98 ; p=$ 0.03). In-hospital mortality (32.1\% vs. $27.3 \% ; p>0.999)$ and institutionalization at discharge $(36.4 \%$ vs. $21.1 \%$; $p=$ 0.258 ) were similar between patients with and without stroke.
\end{abstract}

Conclusion: Incident stroke complicating COVID-19 in old patients was associated with active smoking, previous history of stroke, and low BMI. Acute stroke did not influence early mortality or institutionalization rate at discharge.

Keywords: COVID-19, Stroke, Cerebrovascular, Ischemic stroke, Hemorrhagic stroke

\footnotetext{
* Correspondence: Aline.Mendes@hcuge.ch

'Division of Geriatrics, Department of Rehabilitation and Geriatrics, University

Hospitals of Geneva and Faculty of Medicine, Chemin du Pont-Bochet 3,

1226 Thônex, Geneva, Switzerland

Full list of author information is available at the end of the article
}

C C The Author(s). 2021 Open Access This article is licensed under a Creative Commons Attribution 4.0 International License, which permits use, sharing, adaptation, distribution and reproduction in any medium or format, as long as you give appropriate credit to the original author(s) and the source, provide a link to the Creative Commons licence, and indicate if changes were made. The images or other third party material in this article are included in the article's Creative Commons licence, unless indicated otherwise in a credit line to the material. If material is not included in the article's Creative Commons licence and your intended use is not permitted by statutory regulation or exceeds the permitted use, you will need to obtain permission directly from the copyright holder. To view a copy of this licence, visit http://creativecommons.org/licenses/by/4.0/ The Creative Commons Public Domain Dedication waiver (http://creativecommons.org/publicdomain/zero/1.0/) applies to the data made available in this article, unless otherwise stated in a credit line to the data. 


\section{Introduction}

Acute cerebrovascular complications have been reported through the course of bacterial and viral infections in both young and older patients [1,2]. Multiple mechanisms may explain the phenomenon, such as a higher prothrombotic state induced by systemic inflammation, an increased incidence of arrhythmia, for example atrial fibrillation, and hypoxia leading to cerebral hypoperfusion, and possibly direct virus-induced vasculitis or endothelitis [3, 4].

Different neurological complications associated with severe acute respiratory syndrome coronavirus 2 (SARS$\mathrm{CoV}-2$ ) infection have been described, such as ischemic and hemorrhagic stroke, seizures, meningitis, encephalitis, and Guillain-Barre syndrome [5-8]. A recent systematic review polled 135 cases of ischemic stroke in patients with coronavirus disease 2019 (COVID-19), showing a stroke incidence varying from 0.9 to $2.7 \%$ [9]. Notably, acute stroke in the course of COVID-19 was associated with higher severity of respiratory symptoms and mortality in the acute phase.

However, the majority of studies available describe younger populations and little knowledge exists on acute stroke in old and very old patients with COVID-19. The overall incidence of stroke increases with age, as the general prevalence of cerebrovascular risk factors such as hypertension, diabetes, dyslipidemia, and atrial fibrillation. Likewise, older patients with COVID-19 present worse disease outcomes than younger patients, with increased mortality [10], having led to characterize them as a group at risk for more severe disease course and complications.

This study aimed to describe the incidence, and clinical and imaging characteristics of stroke, as well as their relationship with early mortality and destination at discharge, in a population of old and very old patients hospitalized with COVID-19. We hypothesized that the incidence of stroke in our COVID-19 population was higher than the one described in the literature, and that outcomes were worse.

\section{Methods}

\section{Design, setting and population}

This monocentric cross-sectional retrospective study analyzed patients hospitalized in geriatric wards of Geneva University Hospitals. Hospitalized patients with COVID-19 had one or more of these clinical features: a) pneumonia with a severity assessed by the CURB-65 score $\geq 2$, b) new dependence on oxygen or increase of oxygen needs, c) a respiratory rate $\geq 20$ breaths/minute, d) a decompensated chronic disease, e) severely altered general state of health, f) deteriorating clinical course.

We analyzed data from a total of 265 patients hospitalized with SARS-CoV-2 infection between March 13th,
2020 and May 17th, 2020. The geriatric hospital is part of Geneva University Hospitals, which were responsible during the first wave of the COVID-19 pandemic for hospitalizing all patients of its served population of approximately 500,000 . This study was carried out in accordance with the STrengthening the Reporting of OBservational studies in Epidemiology (STROBE) statement. This study was authorized by the institutional board of the University Hospitals of Geneva and accepted by the Geneva's committee for research ethics (project ID: 2020-00819).

\section{Data collection}

Data regarding demographics, comorbidities, clinical symptoms, and laboratory analyses were retrospectively collected by one research nurse. In general, all information was obtained within the first $24 \mathrm{~h}$ of hospitalization in an acute ward. The geriatric hospital's wards are managed by medical staff trained in internal medicine and geriatrics and can provide general medical care, such as intravenous pharmacotherapy and non-invasive oxygen support (by nasal cannula and face mask, allowing an increase of the fraction of inspired oxygen from 24 to $65 \%)$. Discharge criteria were an improvement of acute illness with subsequent transfer to a rehabilitation ward, or discharge to home or to a nursing home. For patients presenting worsening symptoms and unfavorable evolution, end-of-life care was implemented on the ward with consultation of palliative mobile teams. The diagnosis of COVID-19 was defined as a positive reverse transcription polymerase chain reaction (RT-PCR) test for SARSCoV-2 on a nasopharyngeal swab. Patients with negative virus detection by RT-PCR $(18 / 265 ; 6.8 \%)$ but a high clinical suspicion of disease were also diagnosed with COVID-19 [11].

The Functional Independence Measure (FIM) was performed by a nurse, based on observation during the first $24 \mathrm{~h}$ after hospital admission. It reflects functional status and physical function, with a point score ranging from 18 to 126, higher scores corresponding to better functionality [12]. The Clinical Frailty Score (CFS) was calculated by the physician in charge, reflecting the condition of older patients before hospitalization [13]. Higher CFS scores (from 5 to 8 ) correspond to more severe degrees of frailty, with a terminally ill patient assigned the highest score of 8 . The Cumulative Illness Rating ScaleGeriatric (CIRS-G) was performed at admission, measuring a patient's comorbidity burden by taking into account chronic diseases as well as the severity of acute illnesses, with higher scores representing a higher overall disease burden [14]. The severity of respiratory symptoms was assessed using the Pneumonia Severity Index (PSI) [15] and the abovementioned CURB-65 [16], which varies from 0 to 5 , with higher scores being associated with higher mortality. For patients diagnosed with stroke, 
we computed the Modified Ranking Score (MRS) [17], which assesses functional recovery after a stroke event, as well as the $\mathrm{CHA}_{2} \mathrm{DS}_{2}$-VASc [18] and HAS-BLED [19] scores for thromboembolic and bleeding risks, respectively.

Cerebrovascular complications were defined as a diagnosis of stroke with neuroimaging confirmation by $\mathrm{CT}$ or MRI, including both ischemic stroke and intracranial hemorrhage. We included all cases of stroke having occurred during hospitalization, between the moment of COVID-19 diagnosis and hospital discharge or death. Hence, stroke diagnoses documented during acute and rehabilitation hospital stays were included in the analysis. For all stroke cases identified, an extensive review of the electronic medical record and imaging results was performed by a geriatrician and, for the purpose of this study, all images were reviewed by the same neuroradiologist.. Stroke cases were classified with respect to their localization, extent of ischemia or hemorrhage, and vascular territory [20]. In general, all patients that were suspected to present a stroke underwent standardized neuroimaging by CT or MRI, routinely performed according to in-house protocols.

\section{Statistical analysis}

Categorical variables are expressed as numbers and proportions, while continuous variables appear as means and standard deviations. A two-group comparison (patients with and without stroke) was performed using Fisher's exact test and independent $\mathrm{t}$-test for categorical and continuous variables, respectively. For the $\mathrm{CHA}_{2} \mathrm{DS}_{2}$-VASc and HAS-BLED scores from the stroke group, results are expressed as medians with minimum and maximum values. Because of the low number of stroke occurrences, only univariate logistic regression models were calculated to identify stroke predictors. The variables selection was based on statistically significant differences observed in the two-group comparison (patients with and without stroke). Furthermore, for the significant variables, we performed a trend analysis to study the relationship with stroke occurrence [21].

Statistical analysis was performed using Stata software version 16.1 (Stata Corp., College Station, TX, USA).

\section{Results}

\section{Characteristics of the study population and stroke risk factors}

The study population consisted of 265 patients with a mean age of $85.9 \pm 6.5$ years, $43 \%$ were male, and the inhospital mortality rate was $32.1 \%$. Acute stroke was confirmed in 11 (4.15\%) patients (Fig. 1). Mortality was similar between patients with (32.1\%) and without stroke (27.3\%, $p>0.999)$, and there were no differences regarding age, sex, or length of stay in an acute ward.
Stroke patients had a higher prevalence of active smoking $(27.3 \%$ vs. $4.8 \% ; p=0.019)$, as well as a history of previous stroke $(45.5 \%$ vs. $13.8 \% ; p=0.014)$. On the other hand, tiredness was less frequently reported in the group of stroke patients $(9.1 \%$ vs. $50.2 \% ; p=0.010)$. Interestingly, stroke patients had a lower BMI than those without stroke ( $20.7 \pm 3.5$ vs. $24.9 \pm 6.4 ; p=0.002)$. While their mean BMI value was within the "normal" range, $45.5 \%$ of calculated BMIs were in the underweight range $\left(<20 \mathrm{~kg} \times \mathrm{m}^{-2}\right)$, while no patient with acute stroke was classified as obese (BMI $\geq 30 \mathrm{~kg} \times \mathrm{m}^{-2}$ ) (Fig. 2). The trend towards a lower BMI in the stroke group was statistically significant $(p=0.038)$.

There were no differences regarding other cerebrovascular risk factors, except for dyslipidemia, which was more frequent in stroke patients, but with a borderline statistically significant $p$-value $(63.6 \%$ vs. $33.2 \% ; p=$ 0.051). Similarly, we did not observe differences in comorbidity burden, functional status, frailty, the severity of COVID-19, or the occurrence of other thromboembolic events between the two groups (Table 1).

In an univariate logistic regression model of stroke prediction, active smoking and previous stroke remained significant predictors, increasing by more than seven times and by more than five times, respectively, the risk of stroke. Similarly, each additional point in BMI was associated with a reduced risk of stroke by approximately 14\% (Table 2).

\section{Stroke characteristics and prognosis}

Of the 11 patients with acute stroke, $81.8 \%$ were ischemic $(9 / 11)$ and $18.2 \%$ hemorrhagic $(2 / 11)$. The stroke events occurred after an average of 15.2 days from COVID-19 diagnosis, and the majority of patients presented with stroke during the acute care stay $(8 / 11$; $72.7 \%$ ). Three patients had a simultaneous diagnosis of COVID-19 and acute stroke, whereas another three patients suffered a stroke on a geriatric rehabilitation ward (Supplementary Table S2). An altered state of consciousness and/or delirium were the most frequent clinical manifestations of stroke, reported in $81.8 \%$ of cases (9/ 11). In five patients (45.5\%), a focal neurological deficit was present at the time of imaging by CT or MRI. Thromboembolic risk assessed by the CHA2DS2-VASc score showed a median score of 5 (range, 3-7), and a HAS-BLED score of 3 (range, 1-5).

Large vessel occlusion was reported in $22.2 \%$ of ischemic stroke cases (2/9). Furthermore, strokes were mainly limited to one side (5/9 right, 3/9 left) and the middle cerebral artery territory was affected in more than half of all cases $(5 / 9 ; 55.5 \%)$, followed by the posterior cerebral artery (3/9), and vertebrobasilar territories (2/9). Ischemic lesions in multiple territories were found in two cases (Supplementary Table S1). 


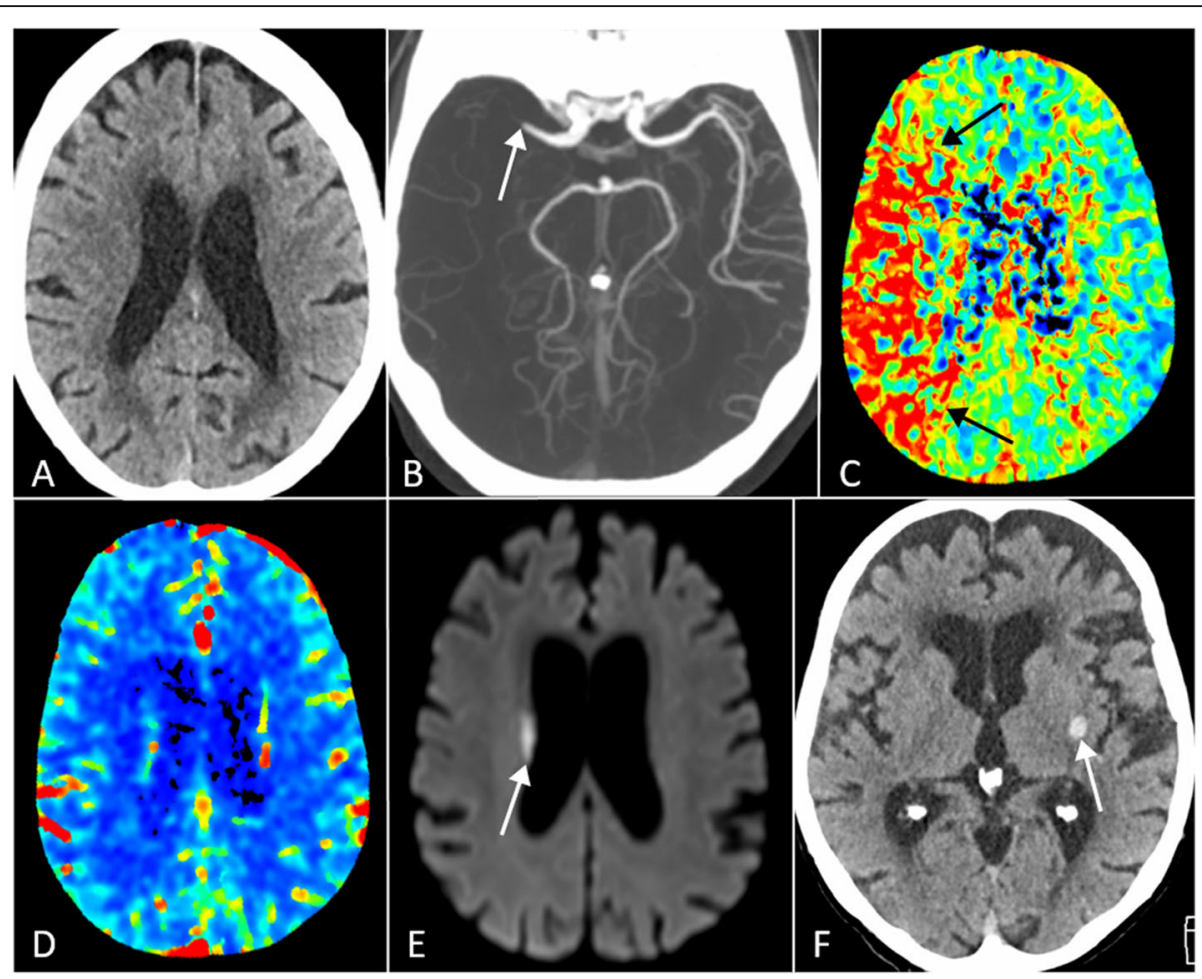

Fig. 1 Illustrative images of neurologic complications in older patients hospitalized with COVID-19 pneumonia. a, b, c, d, and e, CT and MRI images of an 89-year-old woman with left-sided hemiplegia. $\mathbf{a}$, Non-contrast head CT did not show early CT signs of ischemia. $\mathbf{b}$, CT angiogram showed occlusion of the right middle cerebral artery (arrow). c, Perfusion CT mean transit time (MTT) images showed prolonged MTT in the entire right middle cerebral artery territory (arrows), whereas perfusion CT derived cerebral blood volume (d) remained symmetric between both hemispheres. e, Diffusion-weighted image of MRI study obtained one day later and after intravenous thrombolysis showed a small area of infarction in the right corona radiata (arrow). f, Non-contrast head CT image of an 84-year-old woman with obnubilation showed an isolated focus of intraparenchymal hemorrhage in the left lentiform nucleus (arrow). No evidence of underlying vascular or tumoral pathology was found on subsequent MRI (not shown)

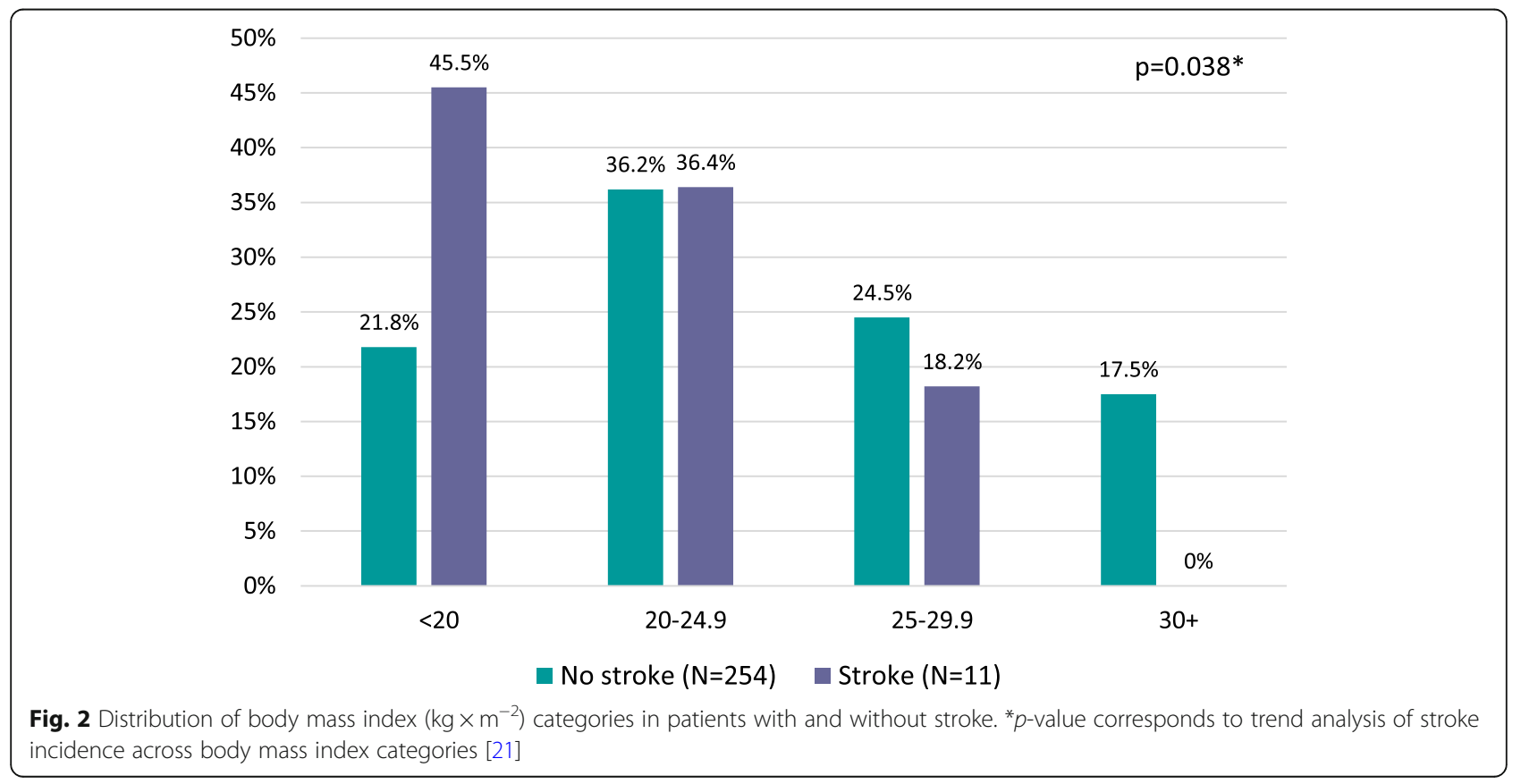


Table 1 Characteristics of patients with ischemic and hemorrhagic types of acute stroke compared to those without stroke

\begin{tabular}{|c|c|c|c|c|}
\hline Characteristics & Total & No stroke & Stroke & $p$ value \\
\hline & $N=265$ & $N=254$ & $N=11$ & \\
\hline Age, years & $85.9 \pm 6.5$ & $85.8 \pm 6.6$ & $87.1 \pm 4.5$ & 0.398 \\
\hline Length of stay in acute care, days & $12.6 \pm 7.7$ & $12.7 \pm 7.7$ & $11.9 \pm 7.8$ & 0.645 \\
\hline Male sex & $114(43.0 \%)$ & 109 (42.9\%) & $5(45.5 \%)$ & $>0.999$ \\
\hline Help in ADL/IADL & $127(47.9 \%)$ & $121(47.6 \%)$ & $6(54.5 \%)$ & 0.762 \\
\hline Mortality & $85(32.1 \%)$ & $82(32.3 \%)$ & $3(27.3 \%)$ & $>0.999$ \\
\hline Number of medications & $7.4 \pm 4.1$ & $7.4 \pm 4.1$ & $6.4 \pm 3.0$ & 0.286 \\
\hline Heart failure & $93(36.5 \%)$ & $90(36.9 \%)$ & $3(27.3 \%)$ & 0.750 \\
\hline COPD & $30(11.4 \%)$ & $27(10.7 \%)$ & $3(27.3 \%)$ & 0.117 \\
\hline Active smoking & $15(5.7 \%)$ & $12(4.8 \%)$ & $3(27.3 \%)$ & 0.019 \\
\hline Kidney disease & $74(28.2 \%)$ & 70 (27.9\%) & $4(36.4 \%)$ & 0.510 \\
\hline Diabetes under treatment & $63(24.0 \%)$ & $60(23.9 \%)$ & $3(27.3 \%)$ & 0.728 \\
\hline Cognitive impairment & $134(51.0 \%)$ & $127(50.4 \%)$ & 7 (63.6\%) & 0.540 \\
\hline Active neoplasia & $23(8.8 \%)$ & $22(8.8 \%)$ & $1(9.1 \%)$ & $>0.999$ \\
\hline History of coronary disease & $36(13.6 \%)$ & $35(13.8 \%)$ & $1(9.1 \%)$ & $>0.999$ \\
\hline History of stroke & $40(15.2 \%)$ & $35(13.8 \%)$ & $5(45.5 \%)$ & 0.014 \\
\hline Atrial fibrillation & $61(23.1 \%)$ & $58(22.9 \%)$ & $3(27.3 \%)$ & 0.719 \\
\hline Hypertension & 187 (70.8\%) & 179 (70.8\%) & $8(72.7 \%)$ & $>0.999$ \\
\hline Dyslipidemia & 91 (34.5\%) & $84(33.2 \%)$ & $7(63.6 \%)$ & 0.051 \\
\hline PE or DVT & $6(2.26 \%)$ & $6(2.36 \%)$ & 0 & $>0.999$ \\
\hline BMl, $\mathrm{kg} \times \mathrm{m}^{-2}$ & $24.8 \pm 6.4$ & $24.9 \pm 6.4$ & $20.7 \pm 3.5$ & 0.002 \\
\hline Asymptomatic & $22(8.5 \%)$ & $19(7.7 \%)$ & $3(27.3 \%)$ & 0.056 \\
\hline Cough & $160(61.5 \%)$ & $155(62.2 \%)$ & $5(45.5 \%)$ & 0.344 \\
\hline Dyspnea & $99(38.1 \%)$ & $95(38.2 \%)$ & $4(36.4 \%)$ & $>0.999$ \\
\hline Tiredness & $126(48.5 \%)$ & $125(50.2 \%)$ & $1(9.1 \%)$ & 0.010 \\
\hline Falls & $30(11.5 \%)$ & $28(11.2 \%)$ & $2(18.2 \%)$ & 0.369 \\
\hline Delirium & $53(20.4 \%)$ & $49(19.7 \%)$ & $4(36.4 \%)$ & 0.242 \\
\hline FIM (18-126) & $71.8 \pm 29.4$ & $72.2 \pm 29.7$ & $62.1 \pm 20.7$ & 0.222 \\
\hline CIRS-G (0-56) & $19.1 \pm 6.2$ & $19.0 \pm 6.3$ & $20.3 \pm 2.3$ & 0.170 \\
\hline$C F S \geq 5$ & 190 (80.9\%) & $182(80.5 \%)$ & $8(88.9 \%)$ & $>0.999$ \\
\hline PSI (0-395) & $126.1 \pm 53.9$ & $125.9 \pm 54.7$ & $130.7 \pm 32.3$ & 0.650 \\
\hline CURB-65 & & & & 0.960 \\
\hline $1-2$ & $168(63.6 \%)$ & $161(63.6 \%)$ & $7(63.6 \%)$ & \\
\hline 3 & $86(32.6 \%)$ & $82(32.4 \%)$ & $4(36.4 \%)$ & \\
\hline $4-5$ & $10(3.8 \%)$ & $10(4.0 \%)$ & $0(0.0 \%)$ & \\
\hline $\mathrm{FiO}_{2}, \%$ & $26.4 \pm 9.6$ & $26.5 \pm 9.6$ & $24.2 \pm 7.5$ & 0.394 \\
\hline Lymphocytes, G/l & $1.2 \pm 1.3$ & $1.2 \pm 1.3$ & $1.0 \pm 0.5$ & 0.361 \\
\hline Pro-brain natriuretic peptide, pg/ml & $5904.0 \pm 10,525.5$ & $5129.4 \pm 8216.0$ & $25,657.8 \pm 32,622.7$ & 0.297 \\
\hline C-reactive protein, mg/l & $67.8 \pm 72.0$ & $66.4 \pm 71.1$ & $98.1 \pm 89.1$ & 0.270 \\
\hline
\end{tabular}

Abbreviations: $A D L$ activities of daily living, IADL instrumental activities of daily living, COPD chronic obstructive pulmonary disease, $P E$ pulmonary embolism, $D V T$ deep vein thrombosis, BMI body mass index, FIM Functional Independence Measure, CIRS-G Cumulative IIIness Rating Scale-Geriatric, CFS Clinical Frailty Score, PSI pneumonia severity index, $\mathrm{FiO}_{2}$ Fraction of inspired oxygen 
Table 2 Univariate logistic regression models for stroke predictors

\begin{tabular}{llll}
\hline & OR & $\mathbf{9 5 \% ~ C l}$ & $\boldsymbol{p}$ value \\
\hline Active smoking & 7.44 & $1.75-31.64$ & 0.007 \\
Previous stroke & 5.19 & $1.50-17.92$ & 0.009 \\
Body mass index & 0.86 & $0.74-0.98$ & 0.03 \\
\hline
\end{tabular}

A cardioembolic cause was identified in 3 cases (44.5\%), followed by suspected arterio-arterial embolism in 2 cases, and small-vessel occlusion in 1 case. Furthermore, one patient presented a border zone infarct as a consequence of systemic hypoperfusion. Ischemic stroke was classified as cryptogenic in two cases, with no etiology determined in acute workup.

By the end of the hospital stay, three patients (27.3\%) died between 3 and 6 days after the stroke occurrence. In-hospital mortality rates were similar between patients with and without acute stroke, as well as institutionalization rates at hospital discharge $(21.1 \%$ vs $36.4 \%$; $p=0.258)$. All survivors presented moderate to severe disability at discharge (Supplementary Fig. S1).

\section{Additional features in neuroimaging}

There was a high burden of cerebral small vessel disease in patients with stroke, with more than half of patients presenting concomitant lacunes (54.5\%). Significant white matter lesions were described in $81.8 \%$ of cases and $45.5 \%$ of patients had at least one cerebral microbleed, in a classical deep or lobar topography. There was no evidence of features such as meningitis, encephalitis, or vasculitis.

\section{Discussion}

In this study, we report a higher incidence of stroke in a population of old and very old patients with COVID-19, compared to previous descriptions in younger cohorts. However, stroke did not increase the risk of dying, and old and very old patients that survived COVID-19 and an acute stroke had similar outcomes than those without this complication. Importantly, active smoking, previous stroke history, together with a low BMI, were significant predictors of cerebrovascular complications in this age group. Stroke was frequently manifested by delirium and/or altered state of consciousness, and the middle cerebral artery territory was the most frequently affected brain region.

The higher incidence of stroke in this study compared to previous reports is probably the result of the higher age and the consequent higher prevalence of cerebrovascular risk factors. Historic population-based studies demonstrated an early case fatality related to all types of stroke varying from 20 to $30 \%$ worldwide [22]. The high rates of overall in-hospital mortality in frail older patients due to COVID-19 possibly overpasses the effect of stroke morbidity alone, explaining the differences regarding a strong association with mortality in younger patients [23]. Long-term follow-up of our patients will clarify whether mortality, institutionalization and rehospitalization rates after hospital discharge will remain similar between groups.

An interesting result of this study was the high prevalence of underweight patients in the stroke group. Although malnutrition is associated with increased length of hospital stay, rehospitalization and mortality after stroke [24], its role as a predictor of stroke occurrence is less well understood, with conflicting evidence [25-27]. Underweight is usually a proxy of malnutrition and sarcopenia, which are possibly related to a higher cardiovascular disease risk [28, 29]. Malnutrition on the other can also be a consequence of a high cardiovascular disease burden, especially in frail older patients [30], in whom a complete nutritional assessment since hospital admission should be part of the clinical workup.

Focal neurological signs were less frequent than delirium as stroke manifestations in this study. The latter may be present in up to $48 \%$ of patients with acute stroke [31] and is usually associated with older age, multiple comorbidities and the extent of ischemia [32-34]. Similarly, a decreased level of consciousness and delayed awaking after stopping sedation were associated with a stroke diagnosis in ICU patients, in the absence of focal deficits [35].

A recent grouped analysis of the first 160 stroke cases reported in the course of COVID-19 showed that $76.6 \%$ of patients presented stroke in the middle cerebral artery territory. In the subgroup of patients older than 70 years (the oldest patient having had 74.3 years of age), it remained the most frequent territory affected, but dropped to $69 \%$ with an increased proportion of vertebrobasilar territory ischemia. We found a similar pattern in our study of still older patients. Importantly, in very old patients, stroke was mostly related to a thromboembolic event and associated with previous risk factors. We found no evidence for a direct neurotropic effect of the SARS-CoV-2 virus, as advocated by other reports [36].

This study has several limitations. Firstly, the crosssectional analysis of cerebrovascular risk factors allowed us to describe the phenotypes of patients at risk, but not to assess causality. Secondly, our study population represents a very specific population of older patients ineligible for intensive care, thus caution is warranted when extrapolating the results to other settings, especially as far as mortality rates and associated factors are concerned. Ineligibility to intensive care was based on patients' wishes and took into account a global geriatric assessment considering severity of the disease, underlying comorbidities, and sometimes also consultation of 
family. Finally, the small number of stroke cases in this study prevented us from calculating multiple variable models of prediction, and some negative findings may be a mere consequence of a lack of statistical power in the analysis.

\section{Conclusion}

In conclusion, clinicians should be aware that incident stroke in patients with COVID-19 is more frequent in old and very old patients, typically manifesting by delirium and decreased level of consciousness, with the middle cerebral artery territory being the most commonly affected. In this study, previous stroke, active smoking, and low BMI were associated with a higher occurrence of stroke in the old and very old age group, and stroke influenced neither the early mortality rate, nor the prevalence of institutionalization by the time of hospital discharge.

\section{Supplementary Information}

The online version contains supplementary material available at https://doi. org/10.1186/s12877-021-02006-2

\section{Additional file 1.}

\section{Authors' contributions}

A.M., M.S. and F.H. were in charge of the conception, writing, and overall presentation of the manuscript. A.M. and F.H. performed the statistical analyses. M.S., C.G., C.S., G.G., D.Z., E.C., M.I.V. and L.G. verified the analytical methods. C.G., C.S., G.G., D.Z., E.C., M.I.V. and L.G participated giving input concerning formulations and provided expertise for the analysis of the results and their presentation. All authors were consulted to discuss the results and contributed to the final version of the manuscript. The author(s) read and approved the final manuscript.

\section{Authors' information}

Not applicable.

\section{Funding}

This study did not receive any funding.

\section{Availability of data and materials}

The datasets used and/or analysed during the current study are available from the corresponding author on reasonable request.

\section{Ethics approval and consent to participate}

Because of the urgent need to develop knowledge regarding COVID-19, patients and members of the public were not directly involved in the study conception. An institutional review board was created to coordinate and validate all COVID-19 related research protocols in the University Hospitals of Geneva. Also, the project was submitted and accepted by Geneva's committee for research ethics (project ID: 2020-00819). Because this is an observational retrospective study, the need for consent to participate was waived by the same committee.

\section{Consent for publication}

Not applicable.

\section{Competing interests}

The authors have no conflict of interest to declare.

\section{Author details}

'Division of Geriatrics, Department of Rehabilitation and Geriatrics, University Hospitals of Geneva and Faculty of Medicine, Chemin du Pont-Bochet 3,

1226 Thônex, Geneva, Switzerland. ${ }^{2}$ Unit of Clinical Nutrition, University
Hospitals of Geneva and Faculty of Medicine, Geneva, Switzerland. ${ }^{3}$ Division of Internal Medicine for the Aged, Department of Rehabilitation and Geriatrics, University Hospitals of Geneva and Faculty of Medicine, Geneva, Switzerland. ${ }^{4}$ Division of Neurology, Department of Neurosciences, University Hospitals of Geneva and Faculty of Medicine, Geneva, Switzerland. ${ }^{5}$ Division of Neuroradiology, Diagnostic Department, University Hospitals of Geneva and Faculty of Medicine, Geneva, Switzerland. ${ }^{6}$ Division of Internal Medicine and Rehabilitation, Department of Rehabilitation and Geriatrics, University Hospitals of Geneva and Faculty of Medicine, Geneva, Switzerland. ${ }^{7}$ Division of Radiology, Diagnostic Department, University Hospitals of Geneva, Geneva, Switzerland

Received: 17 November 2020 Accepted: 30 December 2020 Published online: 14 January 2021

\section{References}

1. Grau AJ, Buggle F, Heindl S, et al. Recent infection as a risk factor for cerebrovascular ischemia. Stroke. 1995;26(3):373-9. https://doi.org/10.1161/ 01.str.26.3.373.

2. Warren-Gash C, Blackburn R, Whitaker H, McMenamin J, Hayward AC. Laboratory-confirmed respiratory infections as triggers for acute myocardial infarction and stroke: a self-controlled case series analysis of national linked datasets from Scotland. Eur Respir J. 2018;51(3). https://doi.org/10.1183/ 13993003.01794-2017.

3. Mehta P, McAuley DF, Brown M, et al. COVID-19: consider cytokine storm syndromes and immunosuppression. Lancet. 2020:395(10229):1033-4. https://doi.org/10.1016/S0140-6736(20)30628-0.

4. Desforges M, Le Coupanec A, Brison E, Meessen-Pinard M, Talbot PJ. Neuroinvasive and neurotropic human respiratory coronaviruses: potential neurovirulent agents in humans. Adv Exp Med Biol. 2014;807:75-96. https:// doi.org/10.1007/978-81-322-1777-0_6.

5. Moriguchi T, Harii N, Goto J, et al. A first case of meningitis/encephalitis associated with SARS-Coronavirus-2. Int J Infect Dis. 2020;94:55-8. https:// doi.org/10.1016/j.jijid.2020.03.062.

6. Mao L, Wang M, Chen S, et al. Neurological manifestations of hospitalized patients with COVID-19 in Wuhan, China: A Retrospective Case Series Study. Social Science Research Network; 2020. Accessed Apr 23, 2020. https:// papers.ssrn.com/abstract $=3544840$.

7. Zhao H, Shen D, Zhou H, Liu J, Chen S. Guillain-Barré syndrome associated with SARS-CoV-2 infection: causality or coincidence? The Lancet Neurology. 2020;19(5):383-4. https://doi.org/10.1016/S1474-4422(20)30109-5.

8. Coen M, Jeanson G, Culebras Almeida LA, et al. Guillain-Barré syndrome as a complication of SARS-CoV-2 infection. Brain Behav Immun. 2020;87:111-2. https://doi.org/10.1016/j.bbi.2020.04.074

9. Tan Y-K, Goh C, Leow AST, et al. COVID-19 and ischemic stroke: a systematic review and meta-summary of the literature. J Thromb Thrombolysis Published online July 13. 2020. https://doi.org/10.1007/s11239-020-02228-y.

10. Mendes A, Serratrice C, Herrmann FR, et al. Predictors of in-hospital mortality in older patients with COVID-19: The COVIDAge Study. J Am Med Directors Assoc. 2020;0(0). https://doi.org/10.1016/j.jamda.2020.09.014.

11. Fatima S, Ratnani I, Husain M, Surani S. Radiological findings in patients with COVID-19. Cureus. 2020;12(4):e7651. https://doi.org/10.7759/cureus.7651.

12. Linacre JM, Heinemann AW, Wright BD, Granger CV, Hamilton BB. The structure and stability of the functional Independence measure. Arch Phys Med Rehabil. 1994:75(2):127-32.

13. Rockwood K, Song X, Macknight C, et al. A global clinical measure of fitness and frailty in elderly people. CMAJ. 2005;173(5):489-95. https://doi.org/10. 1503/cmaj.050051.

14. Salvi F, Miller MD, Grilli A, et al. A manual of guidelines to score the modified cumulative illness rating scale and its validation in acute hospitalized elderly patients. J Am Geriatr Soc. 2008;56(10):1926-31. https:// doi.org/10.1111/j.1532-5415.2008.01935.x.

15. Fine MJ, Auble TE, Yealy DM, et al. A prediction rule to identify low-risk patients with community-acquired pneumonia. N Engl J Med. 1997;336(4): 243-50. https://doi.org/10.1056/NEJM199701233360402.

16. Lim WS, van der Eerden MM, Laing $R$, et al. Defining community acquired pneumonia severity on presentation to hospital: an international derivation and validation study. Thorax. 2003;58(5):377-82. https://doi.org/10.1136/ thorax.58.5.377.

17. Bonita R, Beaglehole R. Recovery of motor function after stroke. Stroke. 1988;19(12):1497-500. https://doi.org/10.1161/01.str.19.12.1497. 
18. Koene RJ, Alraies MC, Norby FL, et al. Relation of the CHA2DS2-VASc Score to Risk of Thrombotic and Embolic Stroke in Community-Dwelling Individuals Without Atrial Fibrillation (From The Atherosclerosis Risk in Communities [ARIC] Study). Am J Cardiol. 2018;0(0). https://doi.org/10.1016/j.amjcard.2018.10.037.

19. Pisters R, Lane DA, Nieuwlaat R, de Vos CB, Crijns HJGM, Lip GYH. A novel user-friendly score (HAS-BLED) to assess 1-year risk of major bleeding in patients with atrial fibrillation: the euro heart survey. Chest. 2010;138(5): 1093-100. https://doi.org/10.1378/chest.10-0134.

20. Fridman S, Bullrich MB, Jimenez-Ruiz A, et al. Stroke risk, phenotypes, and death in COVID-19: systematic review and newly reported cases. Neurology Published online September 15. 2020. https://doi.org/10.1212/WNL. 0000000000010851.

21. Cuzick J. A Wilcoxon-type test for trend. Stat Med. 1985;4(1):87-90. https:// doi.org/10.1002/sim.4780040112.

22. Feigin VL, Lawes CMM, Bennett DA, Barker-Collo SL, Parag V. Worldwide stroke incidence and early case fatality reported in 56 population-based studies: a systematic review. Lancet Neurol. 2009;8(4):355-69. https://doi. org/10.1016/S1474-4422(09)70025-0.

23. Zhou F, Yu T, Du R, et al. Clinical course and risk factors for mortality of adult inpatients with COVID-19 in Wuhan, China: a retrospective cohort study. Lancet. 2020;395(10229):1054-62. https://doi.org/10.1016/S01406736(20)30566-3.

24. Vemmos K, Ntaios G, Spengos K, et al. Association between obesity and mortality after acute first-ever stroke: the obesity-stroke paradox. Stroke. 2011;42(1):30-6. https://doi.org/10.1161/STROKEAHA.110.593434.

25. Cepeda-Valery B, Pressman GS, Figueredo VM, Romero-Corral A. Impact of obesity on total and cardiovascular mortality--fat or fiction? Nat Rev Cardiol. 2011;8(4):233-7. https://doi.org/10.1038/nrcardio.2010.209.

26. Park D, Lee J-H, Han S. Underweight: another risk factor for cardiovascular disease?: a cross-sectional 2013 behavioral risk factor surveillance system (BRFSS) study of 491,773 individuals in the USA. Medicine. 2017;96(48): e8769. https://doi.org/10.1097/MD.0000000000008769.

27. Cui R, Iso H, Toyoshima $H$, et al. Body mass index and mortality from cardiovascular disease among Japanese men and women: the JACC study. Stroke. 2005;36(7):1377-82. https://doi.org/10.1161/01.STR.0000169925.57251.4e

28. Mora S, Yanek LR, Moy TF, Fallin MD, Becker LC, Becker DM. Interaction of body mass index and Framingham risk score in predicting incident coronary disease in families. Circulation. 2005;111(15):1871-6. https://doi. org/10.1161/01.CIR.0000161956.75255.7B

29. Lopez-Jimenez F, Wu CO, Tian X, et al. Weight change after myocardial infarction--the enhancing recovery in coronary heart disease patients (ENR CHD) experience. Am Heart J. 2008;155(3):478-84. https://doi.org/10.1016/j. ahj.2007.10.026.

30. Saitoh M, Ishida J, Doehner W, et al. Sarcopenia, cachexia, and muscle performance in heart failure: review update 2016. Int J Cardiol. 2017;238:511. https://doi.org/10.1016/j.jicard.2017.03.155.

31. Li J, Wang D, Tao W, et al. Early consciousness disorder in acute ischemic stroke: incidence, risk factors and outcome. BMC Neurol. 2016;16(1):140. https://doi.org/10.1186/s12883-016-0666-4.

32. Qu J, Chen Y, Luo G, Zhong H, Xiao W, Yin H. Delirium in the acute phase of ischemic stroke: incidence, risk factors, and effects on functional outcome. J Stroke and Cerebrovascular Dis. 2018;27(10):2641-7. https://doi. org/10.1016/j.jstrokecerebrovasdis.2018.05.034.

33. Carin-Levy G, Mead GE, Nicol K, Rush R, van Wijck F. Delirium in acute stroke: screening tools, incidence rates and predictors: a systematic review. $J$ Neurol. 2012;259(8):1590-9. https://doi.org/10.1007/s00415-011-6383-4.

34. Kotfis K, Bott-Olejnik M, Szylińska A, Listewnik M, Rotter I. Characteristics, risk factors and outcome of early-onset delirium in elderly patients with first ever acute ischemic stroke - a prospective observational cohort study. Clin Interv Aging. 2019;14:1771-82. https://doi.org/10.2147/CIA.S227755.

35. Mishra AK, Sahu KK, George AA, Sargent J, Lal A. Cerebrovascular events in COVID-19 patients. Monaldi Arch Chest Dis. 2020;90(2). https://doi.org/10. 4081/monaldi.2020.1341

36. Ellul MA, Benjamin L, Singh B, et al. Neurological associations of COVID-19. Lancet Neurol. 2020;19(9):767-83. https://doi.org/10.1016/S14744422(20)30221-0

\section{Publisher's Note}

Springer Nature remains neutral with regard to jurisdictional claims in published maps and institutional affiliations.

Ready to submit your research? Choose BMC and benefit from:

- fast, convenient online submission

- thorough peer review by experienced researchers in your field

- rapid publication on acceptance

- support for research data, including large and complex data types

- gold Open Access which fosters wider collaboration and increased citations

- maximum visibility for your research: over $100 \mathrm{M}$ website views per year

At BMC, research is always in progress.

Learn more biomedcentral.com/submissions 